\title{
Muscle Quadriceps Femoris Strength with Postural Balance Level in Elderly
}

\author{
Safun Rahmanto \\ Department of Physiotherapy, University of Muhammadiyah Malang, Indonesia \\ Jalan Bendungan Sutami 188A Kota Malang, East Java 65145 \\ Corresponding author: savun7@gmail.com
}

\begin{abstract}
Background: This study aims to determine the relationship between quadriceps femoris muscle strength with postural level of balance in the elderly. The researchers used a manual muscle testing (MMT) tool for the quadriceps femoris muscle strength component, and on the postural equilibrium component using a tinetti balance test. Subjects studied were elderly aged 60 and above members of the Association of Elderly Mawar Indah Banaran Pabelan and PWRI Wedha Tama Kartasura branch who entered the criteria of inclusion and did not enter exclusion criteria. Objective: The research used cross sectional approach which is done by observation to the sample. The data were collected using total sampling technique from population of 60 people, and considering inclusion and exclusion criteria so that 39 samples were obtained. The test used is nonparametric correlations spearman's rho with equivalence degree 0,05. Results: It can be said the test results are significant. Conclusion: This means that from this study proved a strong relationship between quadriceps femoris muscle strength with postural level of balance in the elderly.
\end{abstract}

Keywords: Quadriceps Femoris, Postural Balance, Elderly

\section{INTRODUCTION}

Crash or sudden fall is an event that is often experienced and complained by the elderly (elderly). They do not realize that it can happen suddenly without feeling the previous symptoms. Usually the elderly who collapsed (lying on the ground or at a lower level) is not accidental (Sundstrup et al, 2010). Based on a survey in the United States community in 1992, there are about $30 \%$ of elderly people aged over 65 years fall every year. Half of these numbers experience recurrent falls (Tinetti 1992). In 1996 there was a falling incident in US society at the age of over 65 years around the population per year. Various factors that influence the fall or collapse in elderly there are some things, namely the host factor (self elderly), activity factors, environmental factors and factors of drugs. Host factors (elderly self) one of them is about the problem of postural balance ((Zech et al, 2010).

The postural balance (balance / stability) is defined as the body's ability to maintain the center of body mass with the stability limit determined by the base of the buffer. The stability limit is a place in a space where the body can keep its position unchanged from the bottom of the buffer. These limits may change according to task, individual biomechanics and environmental aspects (Barker \& Jones, 1996). In postural balance there are interacting components: 1 ) the peripheral (sensory) nervous system that includes visual, vestibular and somatosensory include the propepticides, 2) central nervous 
system processes, especially in basal ganglia, cerebellum and cortex cerebral, 3 ) effector system in which it is associated with the musculoskeletal system which includes muscles, joints and other soft tissues (Granacher, Muehlbauer, \& Gruber, 2011).

The peripheral nervous system includes; vision (visual) helps to orient the body to the space either vertically or horizontally and the objects around it. At the moment of standing, vision helps detect posture changes which are then informed to the central nervous system of the position and movement (Granacher, Muehlbauer, \& Gruber, 2011).The vestibular system provides information to the central nervous system of head movements and positions. The vestibular system is used to balance eye movement and posture response during head movement and help resolve visual conflicts. The somatasensoris system includes propioceptive providing information to the central nervous system of the joints, tendons and muscles regarding body movement on the surface and between the body segments themselves (Schmidt, et al 2009).

The central nervous process that occurs in the basal ganglia is the integration of postural control of the body segment with coordination both at rest and in motion. This activity complements the anti gravity mechanism. The process in the cerebellum is concerned with the reflex setting that occurs during muscle contraction where it is more dynamic at times than static. While the process that occurs in the cerebral cortex is the last integration of reflexes and voluntary movements, it is difficult to know how many reflexes and how much volunteer movement (Schmidt, et al 2009).

The effector system, requires the strength and flexibility of muscles, joints and ligaments are good, so it can produce the right motor response and correct. The musculoskeletal system is the cooperation of muscles, joints, other soft tissues in order to perform normal postural balance movements. In this system, the scope of joint motion, strength, and endurance of the leg muscle groups, ankles, knees, hips, back, neck and eyes. In addition to the factors mentioned above, the balance is also influenced by other factors such as age, motivation, cognition, environment, fatigue, drug influence and previous experience (Granacher, Muehlbauer, \& Gruber, 2011).

Of several factors that affect the balance one of them is related to musculoskeletal. Muscle strength that works to balance one of them is the lower leg (Schmidt, et al, 2009). Research in Japan in 2003 by Tome Ikezoe, Yasuyoshi Akasawa, Alemitsu Tsutou 75 years who had a balance disorder also \pm that 25 elderly women aged had problems with quadricep femoris muscle.

\section{METHOD}

Place of implementation in the Association of Elderly Mawar Indah Banaran Pabelan and PWRI Wedha Tama Ranting Kartasura. The implementation of this study was conducted in July 2008 by measuring the level of quadriceps femoris muscle strength by measuring postural equilibrium levels in the elderly.

The type of research is cross sectional approach that is a research to study the correlation dynamics between risk factors and effects, by approach, observation or data collection at the same time Point Time Approach means that each subject is observed only once and measurement performed on the character status or subject variable at the time of examination. This does not mean that all study subjects were observed at the same time. In this research the methodology application is muscle strength as independent variable while on postural balance as dependent variable.

The population in this study is the elderly in the Association of Elderly Mawar Indah Banaran Pabelan and PWRI Wedha Tama Ranting Kartasura with a total of 50 people. The sampling technique in this research is total sampling / sampling saturation that 
is sampling method by taking all member of population to be sampled (Alimul, 2003), where total population counted 50 people, after grouping based on criteria of inclusion and exclusion 39 samples .

\section{RESULTS AND DISCUSSION}

Table 1. Distribution of Subject Subjects by Age

\begin{tabular}{lcc}
\hline \multicolumn{1}{c}{ Group } & Amount & Percentage \\
\hline Early-age group (55 - 64 years) & 16 & $41,03 \%$ \\
\hline Group of elderly (65 - 70 years). & 8 & $20,51 \%$ \\
\hline $\begin{array}{l}\text { High risk group of elderly (elderly } \\
\text { more than 70 years old). }\end{array}$ & 15 & $38,51 \%$ \\
\hline
\end{tabular}

Table 2. Weight Description Subject Research

\begin{tabular}{ccc}
\hline Weight & Amount & Percentage \\
\hline Thin Body & 12 & $30,8 \%$ \\
\hline Ideal. & 27 & $69,2 \%$ \\
\hline
\end{tabular}

Table 3. Description of Research Subjects by Sex

\begin{tabular}{ccc}
\hline Gender & Amount & Percentage \\
\hline Women & 27 & $69 \%$ \\
\hline Man & 12 & $30 \%$ \\
\hline
\end{tabular}

Table 4. Results of Measuring Muscle Balance

\begin{tabular}{ccccccc}
\hline ko & 0 & 1 & 2 & 3 & 4 & 5 \\
ks & & & & & & - \\
\hline $0-4$ & - & - & - & - & - & - \\
\hline $5-8$ & - & - & - & 2 & - & - \\
\hline $9-12$ & - & - & - & 9 & 7 & 14 \\
\hline $13-16$ & - & - & - & - & 7 & 14 \\
\hline
\end{tabular}

In testing the normality of data with Kolmogorov-Smirnov obtained muscle strength results worth 0.002 and on the balance obtained results 0.004 . So the data distribution is not normal. Result of data test between muscle strength with equilibrium level using nonparametric correlations test with spearman 'rho test type. Correlation value indicates 0.000 for muscle strength and correlation value shows 0.000 for balance. To know the result of a correlation there is a benchmark that if result $<0,05$ result is significant and for $>0,05$ result not significant. With the data obtained from the spearman test 'it can be concluded that there is a relationship between quadriceps femoris muscle strength with postural equilibrium level. 
Table 5. Test Result Relationship Between Muscle Quadriceps Strength Femoris with Postural Balance Rate Using Spearman Rho Test

\begin{tabular}{llll}
\hline & & Muscle Strength & Balance \\
\hline Muscle Strength & Corelasi Coefficient & 1,000 & 0,836 \\
& Sig. (2-tailed) & - & 0,000 \\
\hline Balance & Corelasi Coefficient & 0,836 & 1,000 \\
& Sig. (2-tailed) & 0,000 & - \\
\hline
\end{tabular}

The classification of elderly is divided into 3, namely: group of elderly (55-64 years old) is 16 people or $41,03 \%$, group of elderly (65-70 years) is 8 persons or $20,51 \%$, high risk group of elderly is 15 people or $38.48 \%$. The data obtained, women amounted to 27 subjects with a percentage of $69.2 \%$ and male numbered 12 subjects with a percentage of $30.8 \%$. Body weight based on RBW (Percentage of Relative Body Weight) method of total 39 subjects obtained data: skinny 12 subjects with percentage of $30.8 \%$; normal or ideal weight 27 subjects with a percentage of $69.2 \%$. The ideal weight can help a person's level of balance. The bigger the baban body the more difficult the control of balance and vice versa (Pizzigali, et al, 2011). From the statistical test to find out the correlation between quadriceps femoris muscle strength with postural equilibrium level shows $p$ value is 0,00 . This value indicates a relationship between quadriceps femoris muscle strength with postural level of balance in the elderly.

In postural balance there are interacting components: 1) the peripheral (sensory) nervous system that includes visual, vestibular and somatosensory include the propepticides, 2) central nervous system processes, especially in basal ganglia, cerebellum and cortex cerebral, 3 ) effector system in which it is associated with the musculoskeletal system which includes the muscles, joints and other soft tissues (Guccione 2000). Inside the musculoskeletal system it is explained that to get a good balance requires strength and the fesibility of the muscles. the decline of the musculoskeletal system in the elderly has a very big role to the fall of the elderly or it can be said that the decline of this pure musculoskeletal system belongs to the elderly who has an influence on the postural balance. Muscle atrophy that occurs in the elderly causes a decrease in muscle strength, especially the lower extremity muscles (Granacher, Muehlbauer, \& Gruber, 2011).

The center of mass (mass of the body) is the point at which the amount of force acting on it is equal to zero, so the body is always in balance. The position of the center of the body mass differs in each individual. It depends on age, proportion and body position. In normal individuals who stand still, the center of gravity of the body lies in front of the 2nd sacral vertebra or is $55-57 \%$ of a person's height above the ground. The destabilizing effect of gravity always tries to pull the body down to the earth, resulting in minimal deviation from the center of gravity. Unwittingly, the deviation will be stabilized by the postural equilibrium mechanism around the ankle joint, knee and other body supporters, so that the balance of the body can be maintained (Machadeo, et al, 2010). The greatest quadriceps muscle work is in a half stand (mid stand) position. In such a position quadriceps femoris muscle can work with the nature of static contraction work, extrentric contraction, concentric contraction. Working static contractions when position maintains unchanged position of joint knee joint. Occupational contraction work when the body moves down or the activity from standing to sit. Concentric contraction work as the body moves upward or activity from sitting to standing. 


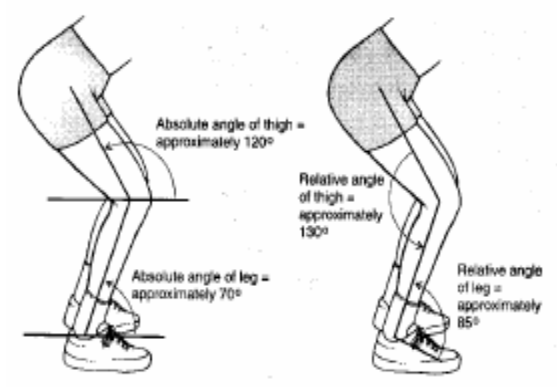

Picture 1. Mid Stand Position (Lattie. 2005 )

At the moment of change the position from sitting to standing quadricep muscle works as a mover. From lever system analysis the position is at lever III. The knee joints as a lever (F) muscle quadriceps as force / effort (E) and body as load (R). When standing position of the knee is not full menggunci, quadriceps muscle also works as a stabilizer with an eccentric contraction. Sistema lever is also in lever III (Burke, et al, 2010).

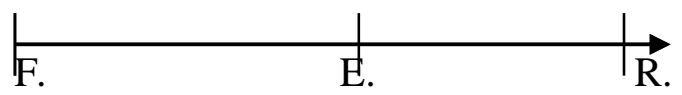

Based on research in Japan in 2003 by Tome Ikezoe, Yasuyoshi Akasawa, Alemitsu Tsutou obtained the result that 25 elderly women aged \pm 75 years who have a balance disorder also have problems in quadriceps muscle. Description of test data between muscle strength and balance level using nonparametric correlations test with spearman 'rho test type. Correlation value indicates 0.000 for muscle strength and correlation value shows 0.000 for balance. With data obtained from the test it can be concluded that there is a relationship between quadriceps femoris muscle strength with postural equilibrium level with significant result of correlation between two variables. There are some limitations from the study, they are: the level of homogeneity that is still lacking, including: environment, habits, work (past), and other conditions that interfere with the homogeneity of the subject, muscle strength measurement using Manual Muscle Testing (MMT) is still subjective, measurement of balance that is sometimes less valid because of less understanding of the subject (elderly is very possible to occur cognitive decline).

\section{CONCLUSION}

It can be concluded from the study that there is a strong relationship between quadriceps femoris muscle strength with postural level of balance in the elderly.

\section{REFERENCES}

Burke, TN, Franca, FJR, De Meneses, F, Rubia, S, \& Pasqual, A, (2010), Postural Control in Elderly Persons with Osteoporosis: Efficacy of an Intervention Program to Improve Balance and Muscle Strength: A Randomized Controlled Trial, American Journal of Physical Medicine \& Rehabilitation, 89(7), 549-556.

Granacher, U, Muehlbauer, \& Gruber, M, (2011), A Qualitative Review of Balance and Strength Performance in Healthy Older Adults: Impact for Testing and Training, Journal of Aging Research, 2012(2012), http://dx.doi.org/10.1155/2012/708905 
Machado, A, Garcia-Lopez, D, Gonzalez-Gallego, J, \& Garatachea, N, (2010), Wholebody vibration training increases muscle strength and mass in older women: a randomized-controlled trial, Scandinavian Journal of Medicine \& Science in Sports, 20(2), 200-207.

Pizzigalli, L, Filippini, A, Ahmaidi, S, Jullien, H, \& Rainoldi, A, (2011), Prevention of Falling Risk in Elderly People: The Relevance of Muscular Strength and Symmetry of Lower Limbs in Postural Stability, Journal of Strength \& Conditioning Research, 25(2), 567-574.

Schmitz, A, Silder, A, Heiderscheit, B, Mahoney, J, \& Thelen, DG, (2009), Differences in lower-extremity muscular activation during walking between healthy older and young adults, Journal of Electromyography and Kinesiology, 19(6), 1085-1091.

Sundstrup, E, Jakobsen, MD, Andersen, JL, Randers, MB, Petersen, J, Suetta, C, \& Krustrup, P, (2010), Muscle function and postural balance in lifelong trained male footballers compared with sedentary elderly men and youngsters, Scandinavian Journal of Medicine \& Science in Sports, 20(1), 90-97.

Zech, A, Hubscher, M, Vogt, L, Banzer, W, Hansel, F, \& Pleifer, K, (2010), Balance Training for Neuromuscular Control and Performance Enhancement: A Systematic Review, Journal of Athletic Training, 45(4), 392-403. 